\title{
The total synthesis of glycolipids from $S$. pneumoniae and a re-evaluation of their immunological activity
}

Seyed Iraj Sadraei ${ }^{1}$, Greg Yousif ${ }^{1}$, S. Maryamdokht Taimoory ${ }^{1,2}$, Maryam Kosar $^{1}$, Samaneh Mehri $^{1}$, Raghd Alolabi ${ }^{3}$, Emmanuel Igbokwe ${ }^{1}$, Jason Toma $^{3}$, Mir Munir A. Rahim ${ }^{3 *}$, John F. $\operatorname{Trant}^{1 *}$

${ }^{1}$ Department of Chemistry and Biochemistry, University of Windsor, Windsor ON, Canada N9B 3P4

${ }^{2}$ Department of Chemistry, University of Michigan, Ann Arbor, MI, USA, 48109-1055

${ }^{3}$ Department of Biomedical Sciences, University of Windsor, Windsor ON, Canada N9B 3P4

\begin{abstract}
:
Invariant natural killer $\mathrm{T}$ cells (iNKT) are responsible for the production of pro-inflammatory cytokines which induce a systemic immune response. They are distinctive in possessing an invariant T-cell receptor that recognizes glycolipid antigens presented by the class I major histocompatibility complex-related protein CD1d, conserved across multiple mammalian species in a class of proteins well-renowned for their high degree of polymorphism. This receptor's first identified antigen is the potent $\alpha$-galactose ceramide, KRN7000, a glycosphingolipid isolated from bacteria that were found on a Japanese marine sponge. The corresponding terrestrial antigen remained unidentified until quite recently, when diacylglycerol-containing glycolipids, reported to activate iNKT cells, were isolated from Streptococcus pneumoniae. We report the total synthesis and immunological re-evaluation of these two glycolipids. The compounds are unable to meaningfully activate iNKT cells. Computational modelling shows that these ligands, while being capable of interacting with the CD1d receptor, create a different surface for the binary complex that makes formation of the ternary complex with the iNKT T-cell receptor difficult. Together these results suggest that the reported activity might have been due to an impurity in the original isolated sample and highlights the importance of taking care when reporting biological activity from isolated natural products.
\end{abstract}

Keywords: Invariant natural killer T cells, S. pneumoniae, immune system, KRN7000, glycolipid, monosaccharide, disaccharide. 


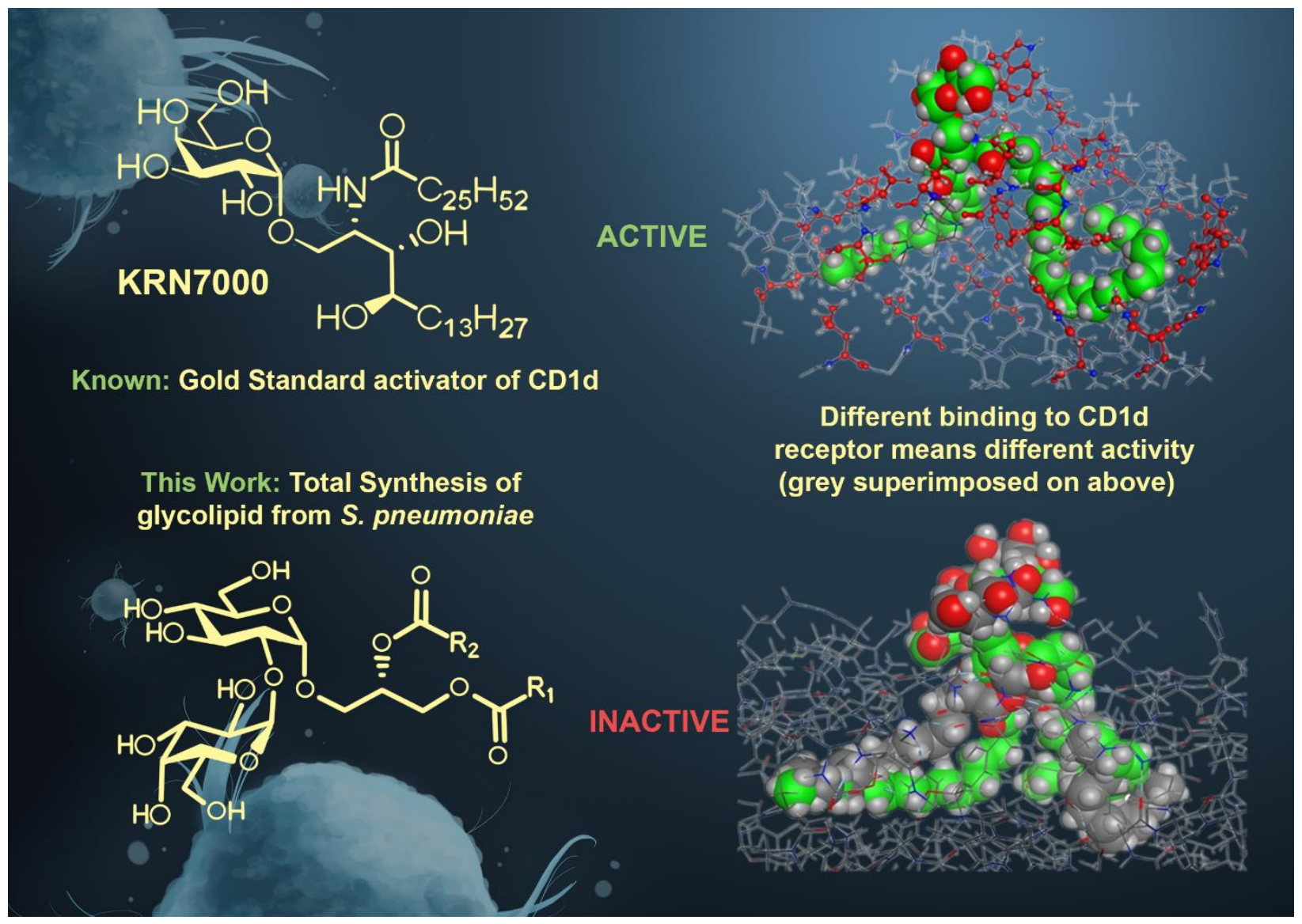




\section{Introduction}

The major histocompatibility complex (MHC) proteome, and their associated T-cell receptors are likely the most polymorphic genes in humans, and likewise one of the least conserved systems between mammalian species, meaning that animal models are only of limited value in MHC immunological research due to a high rate of failure in translation to human clinical populations. ${ }^{1}$ However, there is one notable exception. Both human and mice invariant natural T killer (iNKT) cells express an invariant $\mathrm{T}$ cell receptor for the completely conserved nonpolymorphic MHC class-I-like molecule, CD1d, implying that this protein is important for survival. ${ }^{2}$ This unusual constancy is further emphasized by the ligand recognized by the receptor. Unlike other classical MHC-I molecules that recognize peptides, CD1d is specific for exogenous glycosphingolipids. ${ }^{3}$ The first such ligand identified was KRN7000, 1, whose isolation from a Japanese sea sponge was reported in 1994 (Figure 1). ${ }^{4}$ The molecule was purified from a fraction with highly potent anticancer activity, and upon binding to CD1d activates iNKT cells and induces a potent innate immune system response, leading to the activation of T cell, B cell, dendritic cell and macrophage functions (Figure 1). ${ }^{5}$

KRN7000's unusual mode of action and incredibly potent activity, stimulated a burst of interest in analogues peaking in the mid-2010s $;^{6}$ the pathway's biological role clearly suggests it represents a final line of defense against an existential threat to survival; consequently, this system has been proposed as potentially manipulatable as a potent, if dangerous, defense against cancers, or systemic pathogenic infections. ${ }^{7}$ iNKTs' specificity for these ligands, coupled with their evolutionary stability is unprecedented; they clearly play an essential role in immune defense. However, this research left the mystery as to why the mammalian immune system responds to a glycolipid antigen, isolated from a deep-sea sea sponge, unanswered. A potential solution arose in 2011, when Kinjo and coworkers reported the isolation of two new glycolipid antigens (2 and 3) capable of binding to CD1d (Figure 1). ${ }^{8}$ The glycolipid antigens were isolated from $S$. pneumoniae, which is the leading cause of neonatal sepsis and meningitis, ${ }^{9}$ and until the antibiotic modern era, one of the leading causes of death. ${ }^{10}$ The first was identified as consisting of an $\alpha$-Dglucosylpyranose O-linked to a diacylglycerol where the primary alcohol was esterified with palmitic acid, and the secondary alcohol with cis-vaccenic acid (2). The second fraction had the same core, but with a proposed additional $\alpha$-D-galactosylpyranose attached at the 2-position of the 
glucose (3). ${ }^{8}$ The glycolipid response appeared to be dependent on the inclusion of cis-vaccenic acid, which is highly unusual in mammalian cells, where the trans isomer dominates. ${ }^{11}$
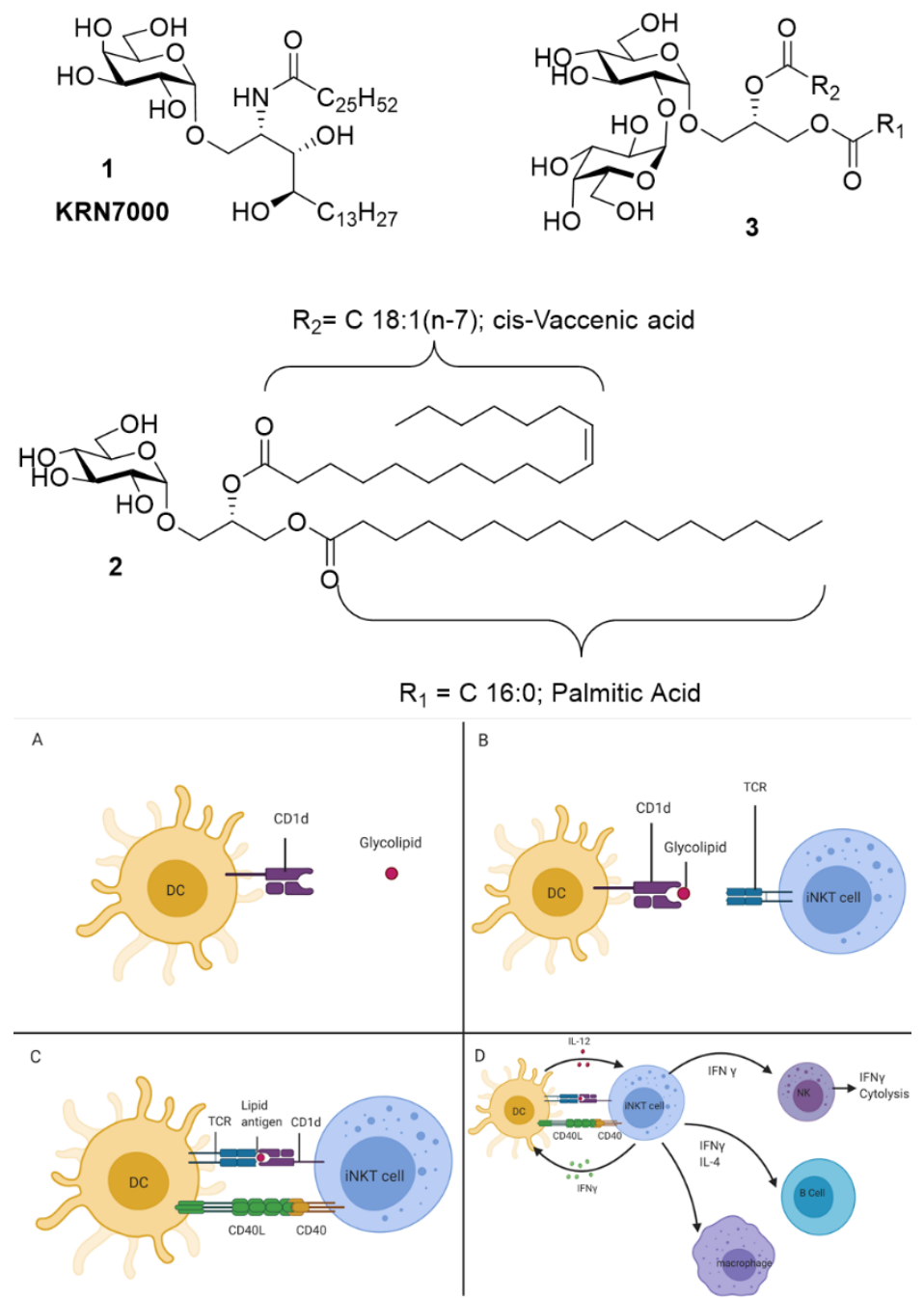

Figure 1. Structure of KRN7000 (1), monosaccharidic glucose diacyl glycerol (2), and disaccharidic galactosyl-glucose diacylglycerol (3). Cartoon representation of the activation of iNKT cells by the glycolipid antigen presented by the CD1d molecule on a subclass of dendritic cells. A) The dendritic cells express CD1d on their surface that can bind the glycolipid antigen; B) This complex can then bind $\mathrm{V}_{\alpha} 14 i$ on invariant NKT cells; C) This then activates the cell, and additional interactions between the cells validate the interaction; D) This leads to the production of cytokines by the iNKT that in turn recruits an immune response from NK cells, B-cells, and macrophages. 
Both glycolipid antigen isolates activated iNKT cells in vivo and in vitro. However, these tests were carried out using very small amounts of isolated glycolipids, ${ }^{9}$ making it impossible to conclusively ascertain whether the activity was due to these compounds or to some minor impurity. Impurities present in isolated samples are notoriously frustrating in immunological research where very small levels of compounds can have outsized biological effects, this is a known issue for synthetic cholesteryl 6-acylglucosides, ${ }^{12}$ where apparently equivalent synthetic batches can have different activity. ${ }^{13}$ Kronenberg and coworkers synthesized 2; however, activity was considerably less for the synthetic version than for the isolated material. This same sugar has since been resynthesized once since this original report, ${ }^{14}$ and its activity was found to be minimal, and far lower, in relative terms, to KRN7000 then first reported. ${ }^{15}$ Disaccharide $\mathbf{3}$ was found to be far more active ${ }^{8}$ but has never been prepared. This is notable as the initial report did not provide incontrovertible proof for the unusual proposed structure. There is only a single other example of a 2-linked Gal-Glc disaccharide coupled to a diacylglycerol reported in the literature, isolated from Listeria and involved in cell wall structure. ${ }^{16}$ The motif is also proposed as the terminal disaccharide in the polysaccharide-containing Yuccoside C. ${ }^{17}$ This particular Gal-Glc disaccharide has never, to the best of our knowledge, been synthesized, let alone conjugated to a diglyceride,

These glycoside diglycerides, incorporating unsaturated fatty acid chains are challenging synthetic targets due to the mutual sensitivity of protecting groups and the esters to standard reagents. The extant synthetic approaches to similar compounds commonly suffer from low efficiency, synthetic flexibility, and stereopurity. ${ }^{18}$ Herein we report a simple total synthesis of both S. pneumoniae glycolipids, a reevaluation of their biological activity, and an in silico investigation of their functional structural biology. We find that they are functionally incapable of activating iNKT cells. We conclude that some of the activity observed in the original report might be attributable to minor impurities present in the evaluated samples, perhaps a glycosphingolipid similar in structure to KRN7000.

\section{Result and Discussion}

Before embarking on this campaign, we developed a synthetic route based on excellent literature precedent and high familiarity with the required reactivity to overcome these challenges. Like Thomas Jefferson, we believed that "the acquisition of the [molecules] this year (2017), as far as the [disaccharide glycolipid], will be a mere matter of marching." ${ }^{19}$ Overconfidence in the face of the new but seemingly familiar is a recurrent and constant error in both military and synthetic 
chemistry campaigns; like Mr. Jefferson, we were gravely disappointed. However, unlike Mr. Jefferson and the American military, we were eventually successful.

Synthesis of monosaccharidic glucose diacyl glycerol, 2 . The synthesis of $\mathbf{2}$ begins with glucose 4 (Scheme 1), which was converted using standard chemistry to the base-stable, non-anchiomericassistance active, ${ }^{20} \beta$ - thiophenol glycoside 5. The diglyceride acceptor, $(S)-(+)-$ Solketal $\mathbf{8}$, was synthesized through a modification of Terivedi's strategy to provide the appropriate protected chiral glycerol; ${ }^{21}$ the change is the use of lead (IV) acetate for the oxidative cleavage of the mannitol di-acetonide 7 rather than the reported sodium periodate, which proved irreproducible in our hands. ${ }^{22}$

The glycosylation is superficially simple; however standard $\alpha$-specific glycosylations failed to provide the desired anomer, all forming the undesired $\beta$ diastereomer of 9 either exclusively or as the major product (See supporting information, 9a). ${ }^{18 a}$, 23 This was highly surprising as the glycosylation appears far simpler than most, but perhaps is affected by interference of Lewis acid co-ordination by the proximal ketal on the acceptor, and was especially problematic as the two anomers were completely inseparable by preparative column chromatography. The best ratio achieved was a disappointing 3:1 ratio of $\alpha$ : $\beta$ anomers of 9 (diethyl ether) in $90 \%$ combined yield, and the mixture of anomers was carried forward with the eventual expectation that separation could be affected in the final step, if necessary, by semi-preparative HPLC. 


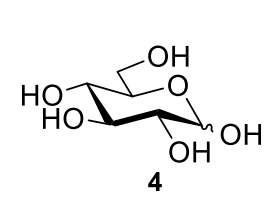

1. $\mathrm{Ac}_{2} \mathrm{O}, \mathrm{NaOAc}$

2. $\mathrm{BF}_{3} \cdot \mathrm{OEt}_{2}, \mathrm{PhSh}$

$\mathrm{CH}_{2} \mathrm{Cl}_{2}$

3. $\mathrm{MeOH}, \mathrm{NaOAc}$

4. $\mathrm{BnBr}, \mathrm{DMF}, \mathrm{NaH}$

$52 \%$

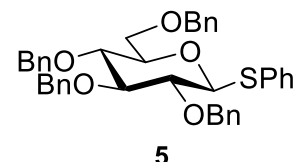

$\overbrace{\mathrm{OH}}^{\mathrm{O}_{\mathbf{O}}}$

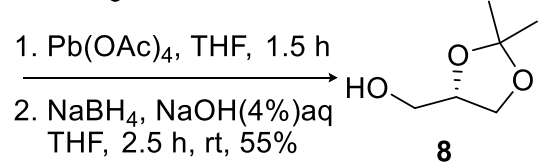

THF, $2.5 \mathrm{~h}, \mathrm{rt}, 55 \%$

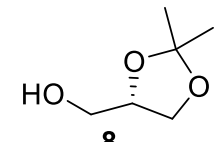

8
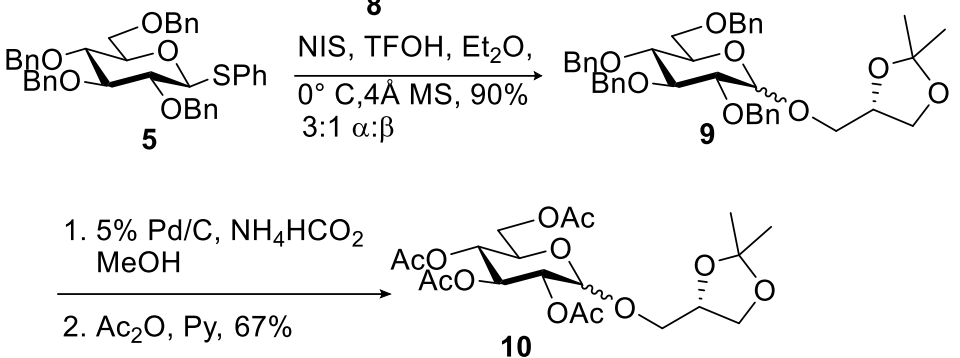

1. $\mathrm{Zn}\left(\mathrm{NO}_{3}\right)_{2} \cdot 6 \mathrm{H}_{2} \mathrm{O}$

$\mathrm{CH}_{3} \mathrm{CN}, 70 \%$

2. Palmitic acid, EDC

DMAP, $\mathrm{CH}_{2} \mathrm{Cl}_{2}, 0^{\circ} \mathrm{C}$

$50 \%$

3. Vaccinic acid, EDC

DMAP, $\mathrm{CH}_{2} \mathrm{Cl}_{2}$, rt, $58 \%$

4. $\mathrm{N}_{2} \mathrm{H}_{4} \cdot \mathrm{H}_{2} \mathrm{O}, \mathrm{EtOH}$,

$44^{\circ} \mathrm{C}, 6 \mathrm{~h}, 55 \%$

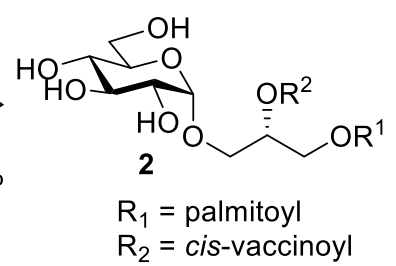

Scheme 1. Synthesis of monosaccharide 2

Having performed their function, the benzyl groups were replaced with acetates, due to the incompatibility of hydrogenolysis with cis-vaccenic acid, to provide fully protected $\mathbf{1 0}$ in two steps. Zinc nitrate hexahydrate in acetonitrile selectively hydrolysed the isopropylidene group of the glyceride to provide the diol. ${ }^{24}$ Sequential esterification, relying on the increased reactivity of the primary alcohol over the secondary alcohol, with palmitic acid $\left(\right.$ at $\left.0{ }^{\circ} \mathrm{C}\right)$ and freshly prepared cis-Vaccenic acid (at ambient temperature due to a more sluggish reaction) ${ }^{25}$ provided the fully protected diglyceride. Following the second esterification, the two anomers surprisingly separated easily by column chromatography as the Rf values, for the first time since $\mathbf{9}$ diverged significantly. 
The reported yields up until the second esterification are for the combined mixture of the anomers; the second esterification, with a $58 \%$ yield, is reported for the recovery of the pure $\alpha$-anomer from the mixture, yield from the $\alpha$-precursor alone was $77 \%$; the $\beta$-anomer, was also isolated and recovered at this point. Finally, the desired deprotected carbohydrate 2, was obtained following global deacetylation using hydazine hydrate in 55\% yield. ${ }^{26}$ Byproducts in this final step ominously included limited desterification and a small amount of deglycosylation. The $\beta$-anomer was likewise deprotected to provide epitopically pure $\mathbf{2 \beta}$.

Synthesis of disaccharidic galactosyl-glucose diacylglycerol, 3. With the monosaccharide in hand, we believed the disaccharide would not prove overly challenging, with the only obstacle being to efficiently obtain the C-2 hydroxyl free precursor required to introduce the galactosyl substituent. The rest of the synthesis should be able to remain strategically unchanged. ${ }^{27}$ Fortunately, we could readily solve this challenge (Scheme 2). As with 2, glucose was transformed to a fully deprotected thioether, this case ethylthiol-derived 11. Kinetic benzylidene formation was followed by acetylation provides $\mathbf{1 2}$. Then, the C-2 hydroxyl was selectively unmasked through Ensley's method of concomitant oxocarbenium formation and acetyl migration to the anomeric position to provide glycosyl acceptor $\mathbf{1 3}$ in $40 \%$ yield. ${ }^{28}$ Multiple glycosylations were investigated to prepare the disaccharide, but simple tricholoacedimidate (TCA) chemistry proved to be sufficiently reliable after a preliminary screen; notably, the reaction was highly sensitive to the stereochemistry of the donor and the Lewis acid. The reaction proceeds only from the $\alpha$-anomer and using $\mathrm{BF}_{3} \cdot \mathrm{OEt}_{2}$. Although we were readily able to generate the $\beta$-anomer of the TCA agent in near analytical purity without purification, we were unable to obtain the $\alpha$ anomer in greater than a 1:1 ratio with the $\beta$ isomer. ${ }^{29}$ Freshly distilled TMSOTf did not catalyze the transformation with either anomer even at elevated temperatures and extended reaction times. Test reactions showed that the reaction was facile with almost any other acceptor, and this recalcitrant reactivity is a function of both donor and acceptor. 

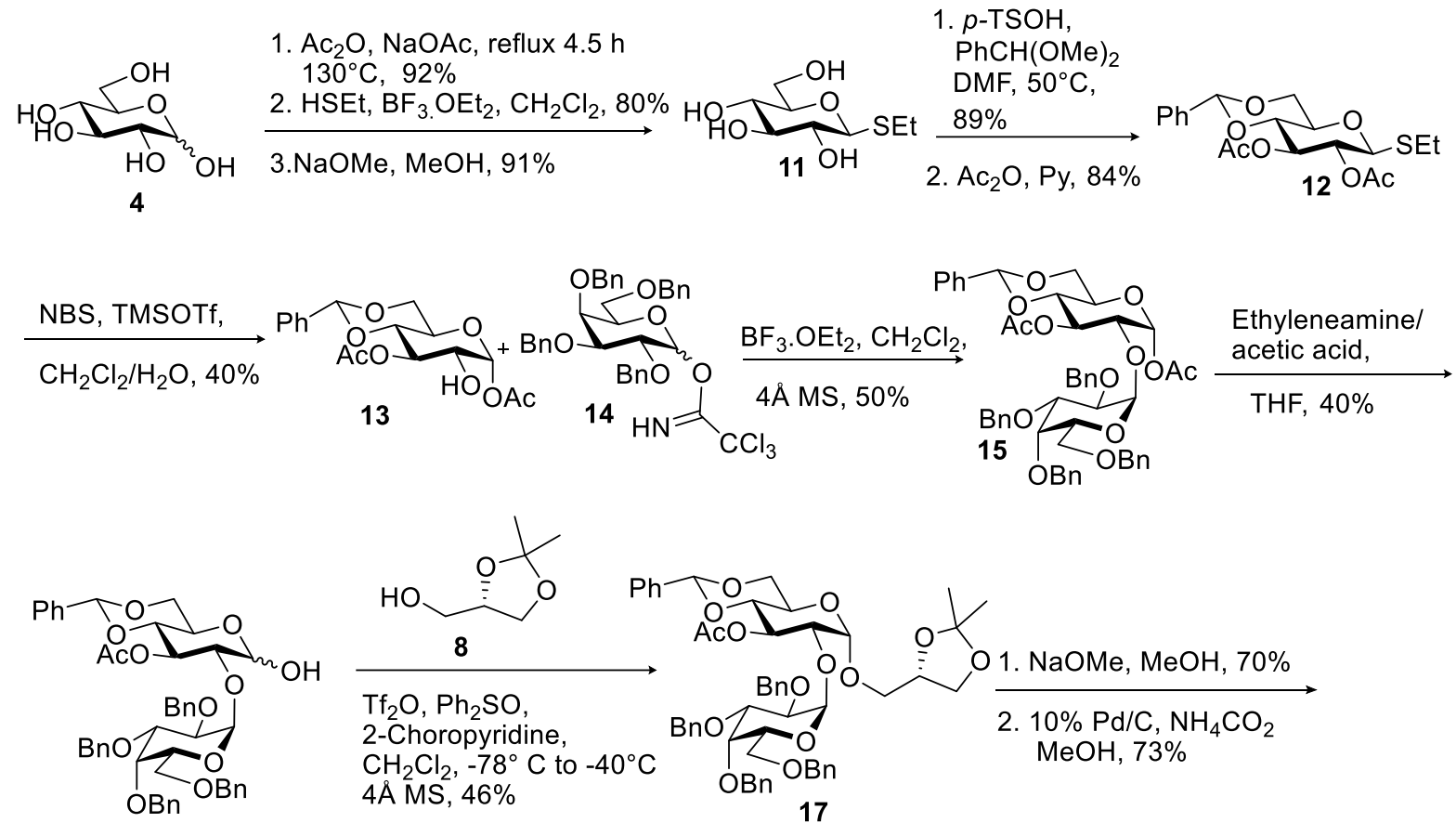

16
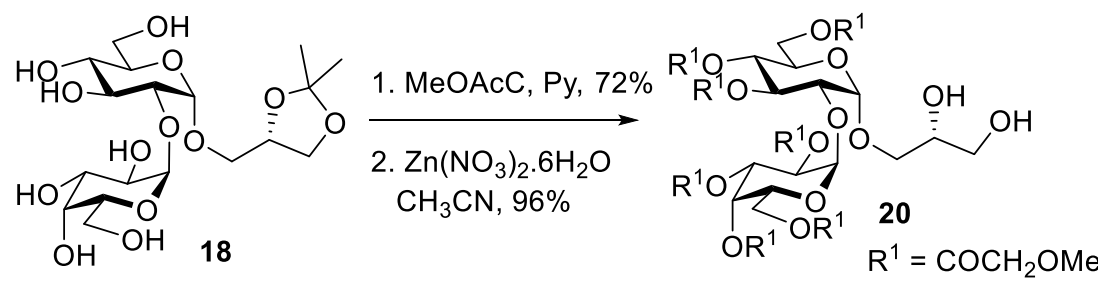

5. Palmitic acid, EDC
DMAP, $\mathrm{CH}_{2} \mathrm{Cl}_{2}, 0^{\circ} \mathrm{C}$ $53 \%$

6. Vaccinic acid, EDC DMAP, $\mathrm{CH}_{2} \mathrm{Cl}_{2}$ $50 \%$
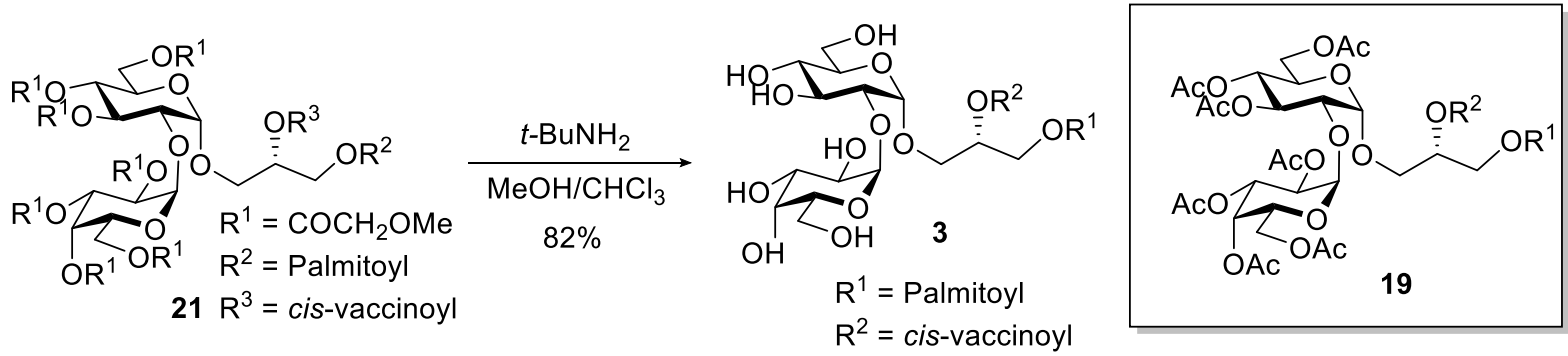

Scheme 2. Synthesis of Disaccharide 3

Anomeric acetates are themselves moderately reactive glycosylation agents $;^{30}$ however, continuing the trend of this campaign, $\mathbf{1 5}$, proved to be a reluctant donor for glyceride acceptor $\mathbf{8}$, and we were unable to convert the $\alpha$ acetate directly. The chemoselective removal of the acetyl group at anomeric position was accomplished via a mixture of ethylene amine and acetic acid in THF at 24 hours, ${ }^{31}$ with the mass balance being unreacted starting material that can be resubjected to reaction conditions (longer reaction times started to result in cleavage of the intersaccharidic bond). To limit the step count, we attempted Savage's glycosylation of the free hydroxyl, which 
was employed for the galactosyl-galactosyl analogue of this current target, using diphenylsulfoxide activated with triflic anhydride and tri-t-butylpyrimidine as base, but this failed to provide any product. ${ }^{31}$ However, increasing the reactivity of the system by using 2chloropyridine as base proved successful, providing 17 , the core of the glycolipid. ${ }^{32}$ The protecting group strategy had been selected to be compatible with the chemistry developed for the monosaccharide. Global deprotection of the carbohydrate protecting groups (without touching the acetonide on the glycerol), proceeded smoothly to $\mathbf{1 8}$.

We then conducted the same sequence used for the monosaccharide to complete the synthesis: peracetylation, acetonide removal, and selective esterifications to generate 19. However, all attempts to cleave the acetates from the sugars without affecting the esters on the glyceride failed. Reagents variously either cleaved all esters, did not react, were unable to provide selectivity, or cleaved the apparently sensitive intersaccharidic bond. Despite a very significant effort, we were unable to remove the acetates in the presence of the esters without damaging the rest of the molecule. A new approach was required.

Consequently, we employed methoxyacetyl groups that can be cleaved by tertbutylamine. ${ }^{33}$ This is an underappreciated protecting group as the deprotection conditions are highly compatible with a wide variety of different functional groups. A full description of an expansion of the potential of this system will be published in due course. Fully deprotected $\mathbf{1 8}$ was acylated, the acetonide removed as before, and the esterifications proceeded without difficulty. Fortunately, the tert-butylamine, unlike any of the other deacylation reagents tested, was gentle enough to evince the final deprotection to provide 3 in $82 \%$ yield. ${ }^{33 \mathrm{c}}$

iNKT activation ability of the synthetic glycolipids. With the materials in hand, we evaluated their ability to induce production of cytokines by CD1d-restricted iNKT cells. We employed the mouse iNKT cell hybridoma DN32.D3, especially well designed for this experiment as it possesses both the CD1d and the unique conserved, invariant $\mathrm{V}_{\alpha} 14 \mathrm{~T}$ cell receptor of iNKT cells, allowing the cells to present antigenic glycolipids and cross-activate each other. This cell line has been used extensively in the past to measure iNKT cell responses, represented by the production of interleukin-2 (IL-2, other cytokines show similar results). ${ }^{34}$ These cells produce IL-2 in response to KRN7000 treatment in a CD1d-dependent manner, making KRN7000 an excellent positive control. Several other glycolipid formulations have also been shown to induce an immune response from these cell types, including bacterial superantigens (SAgs), ${ }^{34 a}$ a series of glycolipids from 
pathogenic bacteria, ${ }^{35}$ including the ones synthesized here,${ }^{8}$ and even a multivalent acetal-free,${ }^{36}$ dendron-supported carbohydrate previously reported by us. ${ }^{34 \mathrm{c}}$ Kinjo and co-workers evaluated the immunogenicity of their isolated glycolipids using a similar system to the one used by our team: mouse $\mathrm{V}_{\alpha} 14 i \mathrm{NKT}$ cell hybridomas were used. ${ }^{8}$ The isolates showed good elicitation of IL-2 from $\mathrm{V}_{\alpha} 14 i \mathrm{NKT}$ cell hybridomas in a CD1d-dependent manner, but no activation of CD1d-reactive non$\mathrm{V}_{\alpha} 14 i \mathrm{NKT}$ cell hybridomas. The team then synthesized the monosaccharide and evaluated the immunogenicity of that system (while also confirming the structure and regiochemistry of the ester groups) and demonstrated that it showed similar activity to the isolated monosaccharide. ${ }^{8}$ This is not the result we observed here. We observe no meaningful IL-2 response from the DN32.D3 cells towards the synthesized glycolipids at either $100 \mathrm{ng} / \mathrm{mL}$ to $1 \mu \mathrm{g} / \mathrm{mL}$ relaive to their background response to media, while KRN7000 showed its typical potent activity in inducing IL-2 production by these cells (Figure 2). 
A
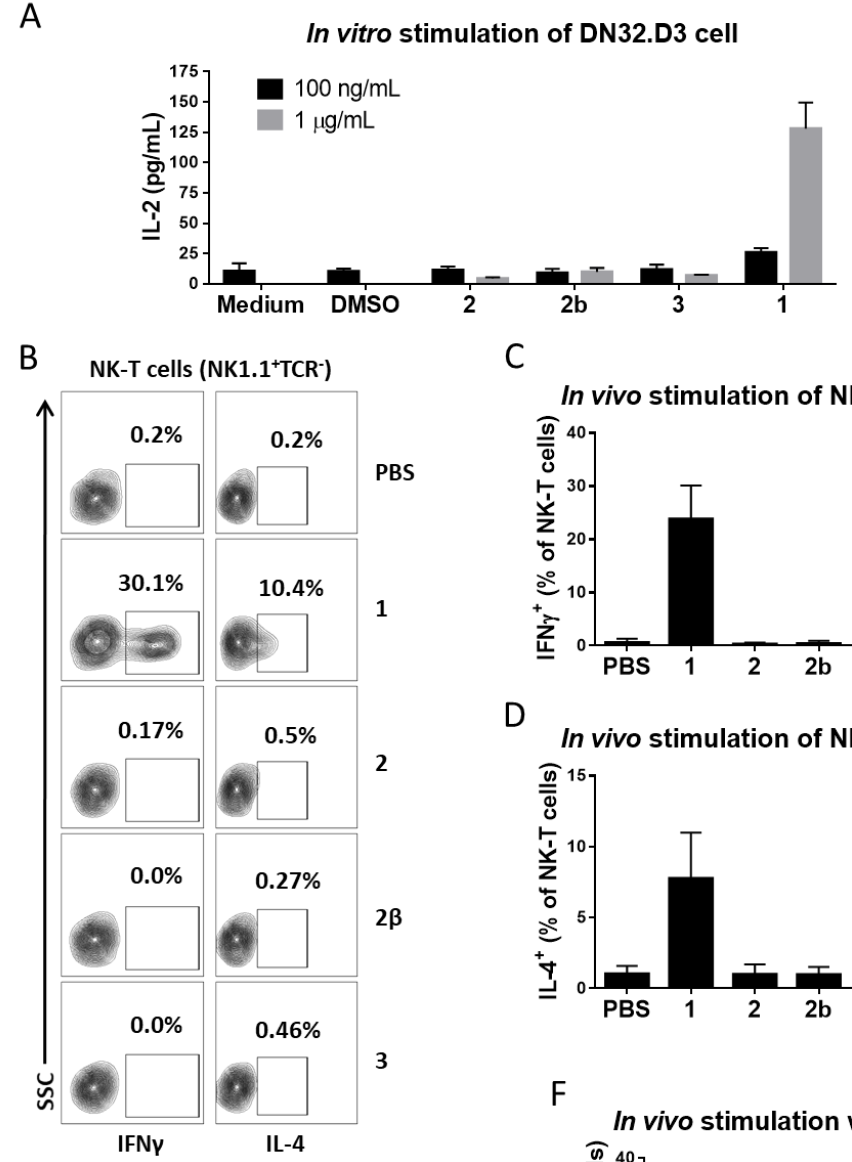

C

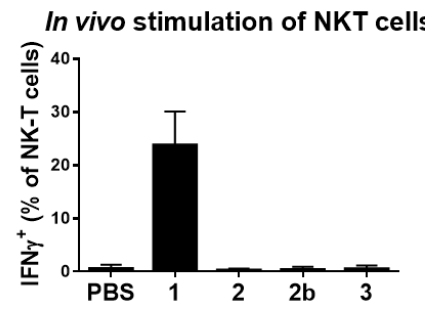

D
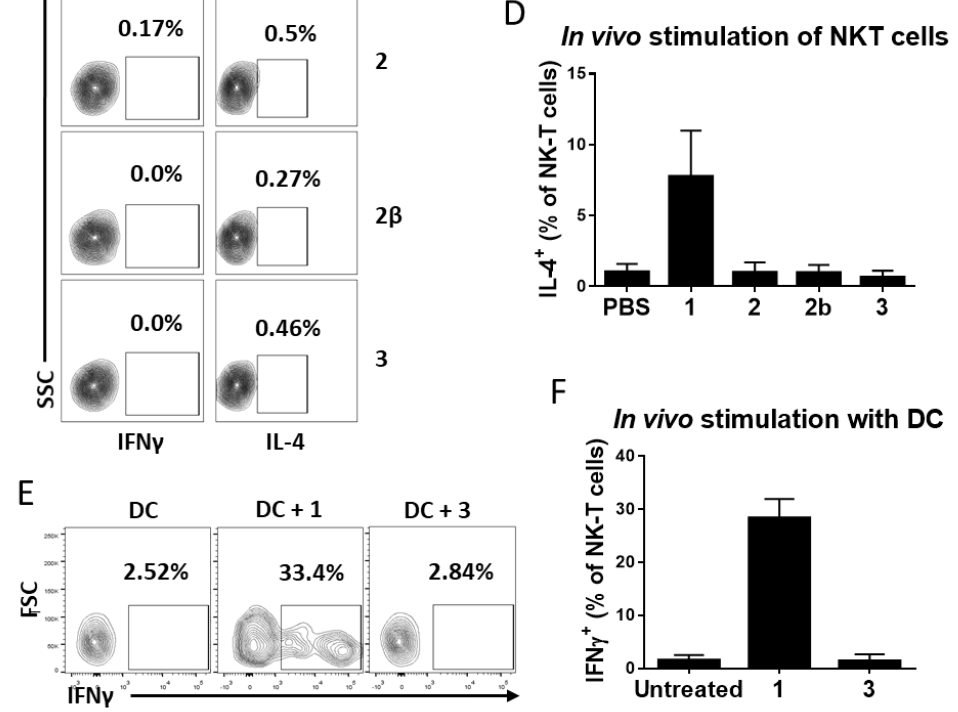

Figure 2. Cytokine production by iNKT cells in response to glycolipid stimulation. A) Elicited IL-2 levels obtained from exposing DN32.D3 cells to the synthesized glycosphingolipids measure by ELISA. Data represent mean \pm standard deviation of triplicate samples; B) Flow cytometry analysis of intracellular IL-4 and IFN $\gamma$ levels in NKT cells $\left(\mathrm{NK} 1.1^{+} \mathrm{TCR} \beta^{-}\right)$in the spleens of 8-12 week-old C57BL/6 mice 2 hours after intraperitoneal injection with the indicated agents $(4 \mu \mathrm{g}$ in $200 \mu \mathrm{L}$ PBS/mouse). Percentage of $\mathrm{IL}_{-} 4^{+}$and IFN $\gamma^{+}$cells are indicated for each treatment. Data represent one out of at least 6 mice in each of the treatment groups; C) Quantification of the IFN $\gamma^{+}$ results from B; D) Quantification of the $\mathrm{IL}_{-} 4^{+}$results from B. Data represent mean \pm standard deviation. E) Flow cytometry analysis of intracellular IFN $\gamma$ levels in NKT cells in the spleens of C57BL/6 mice 24 hours after adoptive transfer of antigen-pulsed DCs. Percentage of IFN $\gamma^{+}$cells are indicated for each treatment. Data represent one out of at least 4-6 mice in each of the treatment 
groups; F) Quantification of the IFN $\gamma^{+}$results from E, representing mean \pm standard deviation. 1, KRN7000; 2, monosaccharidic glucose diacyl glycerol; 2及, monosaccharidic glucose diacyl glycerol ( $\beta$-anomer); 3, disaccharidic galactosyl-glucose diacylglycerol.

This is in stark contrast to the results initially reported by Kronenberg and coworkers, ${ }^{8}$ although it is in line with the work of Williams and coworkers. They have shown that the activity of 2 and many derivatives, appears to be potentially dependent on the particular cell clone involved. ${ }^{15 a}$ This might imply that the mechanism of action may be more complicated than simple binding of the glycolipid to the receptor; note that $\mathbf{1}$ alone is sufficient to activate the Type I iNKT system regardless of the cell clone. Consequently, we resynthesized fresh batches of the glycolipids, repurified them, and re-evaluated the samples obtaining the same result. We further evaluated the ability of the materials to induce iNKT cells stimulation in vivo in C57BL/6 mouse strain. We reasoned that the CD1d-restricted cell line may not provide the full required machinery needed to elicit an $i$ NKT cell response to these modified glycolipids in vitro, that a fully intact immune system could provide. This hybridoma is sufficient for antigens that function directly through the CD1d- $\mathrm{V}_{\alpha} 14 \mathrm{~T}$ interaction, but it is possible that the antigens function like superantigens and activate the iNKTs indirectly. To this end, we treated groups of mice with $4 \mu \mathrm{g}$ dose of the glycolipid antigens and KRN7000 intraparitoneally. Two hours post injection, mice were sacrificed and the percentage of splenic NKT cells expressing IL-4 and IFN $\gamma$ were determined by intracellular staining and flow cytometry analysis. In our experiments NKT cells were recognized as NK1.1 ${ }^{+} \mathrm{TCR} \beta^{-}$lymphocytes. Again, KRN7000 proved a potent stimulator of NKT cells, but none of our synthetic glycolipids showed any significant activity relative to vehicle (Figure 2). Extended in vivo stimulation up to $48 \mathrm{hrs}$ did not elicit any IL-4 and IFN $\gamma$ response in iNKT cells against any of the synthetic glycolipids (not shown). These molecules failed to induce IL-4 and IFN $\gamma$ production by NKT cells in vivo. Finally, to ensure that the glycolipid antigens were accessible by dendritic cells (DC) for presentation on CD1d, we used bone marrow-derived DCs pulsed with the glycolipid antigens before adoptively transferring them to $\mathrm{CD} 57 \mathrm{~B} / 6$ mice to activate NKT cells in vivo. Again, the synthetic glycolipid-pulsed DCs failed to elicit any IFN $\gamma$ production from NKT cells, while KRN7000-pulsed DCs were potent activators of NKT cells (Figure 2). 
One of the differences between this study and the one by the Kronenberg group is in the iNKT cell hybridomas used to evaluate iNKT cell responses. Our cells (DN32.D3) express both CD1d and the invariant $\mathrm{V}_{\alpha} 14 \mathrm{~T}$ cell receptor, allowing the cells to present antigens and activate each other, while the Kronenberg group used an iNKT cell hybridoma which did not express CD1d, therefore, requiring the use of DC or plate-bound CD1d molecules for presentation of antigenic glycolipids. Using $\mathrm{Il}-12^{-/-}$and $\mathrm{Myd} 88^{-/-}$mice, the Kronenberg group demonstrated that iNKT cell responses in their assays were independent of IL-12 and activation of DC via Toll-like receptors, however, the contribution of other pro-inflammatory cytokines induced by their antigenic preparations cannot be completely ruled out. Alternatively, CD1d-dependant presentation of glycolipids to iNKT cells may require additional processing of the isolated glycolipids by DCs. Our in vitro assays are performed in the absence of DCs as antigen presenting cells, therefore, are not subjected to the same factors. Furthermore, our in vivo assay in the immunocompetent mice firmly demonstrate that, unlike KRN7000, which induced iNKT cell stimulation and cytokine production, our glycolipid preparations did not elicit such a response under similar conditions. The contribution of glycolipid preparations in the activation of iNKT cells, if any, appears to be mechanistically different than that of KRN7000.

The difference between the cell lines used by our research group and that of the Kronenberg group is that our cells had the murine MHC receptors removed, leaving only CD1d. ${ }^{8}$ The Kronenberg group's cells still have the other receptors present. Glycolipids do not, as a rule, interact with other MHC receptors, but the possibility remains that this could explain this discrepancy; however, our mice had fully active murine immune systems that are stimulated by KRN7000, and would be sensitive to superantigen effects. Not seeing any response makes it less likely that this would be the mechanism of action.

In all our in vitro and in vivo experiments, KRN7000, with a nearly identical solubility profile, and the same proposed mechanism of action, was a potent activator, while these other glycolipids were not. This suggests that the $i$ NKT system did not co-evolve to recognize the presence of these particular glycolipids, this difference in activity could be ascribed to the manner that they interact with the receptor. Other glycolipids, based on glucuronosyl diacylglycerides ${ }^{37}$ have also been isolated and show substantial activity. ${ }^{38}$ 

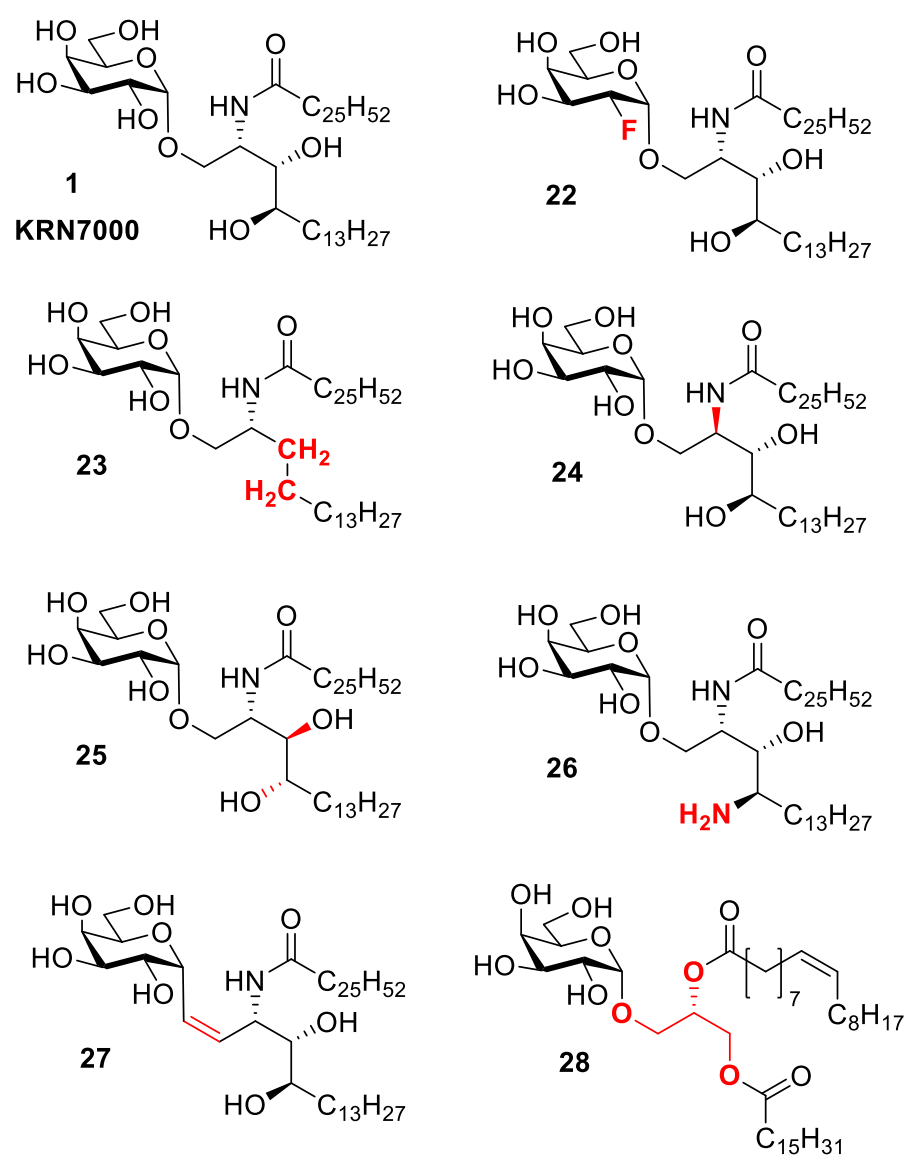

Figure 3. Examples of the modifications to KRN7000 not tolerated by CD1d..

We know that the CD1d-dependent response to glycolipids is exquisitely sensitive to the structure of the glycolipid antigens (Figure 3). The structure-activity relationship studies conducted on KRN7000 have been extensive and have repeatedly reiterated that modifications to the structure are often deleterious to its iNKT cell-activating ability. ${ }^{6}$ Substitution at C2 as in $\mathbf{2 2}$, is not tolerated except by a sugar; nor are the removal of the hydroxyl groups of the phytosphingosine (i.e. 23), changes in stereochemistry of the phytosphingosine (24 and 25), or replacement of the hydroxyl group by an amine 26. Introduction of a $Z$-double bond, 27, also abrogates activity, although the $E$ is tolerated. An important exception is that certain specific galactose diglycerides, such as $\mathbf{2 8}$, do continue to activate the system. Likewise, the glucose derivative of KRN7000 shows very moderate activity. Finally, C-2 substitution of KRN7000 with an $\alpha$-D-galactoside is tolerated in the preliminary studies. Together these modifications suggest the glucose derivatives synthesized here could show activity, but perhaps the multiple modifications simply distort the CD1d antigenbind surface to too great a degree to allow for ternary complex formation with the T-cell receptor. To address this question, we conducted a series of computational analyses. 
Computational Analysis Starting with the published crystal structure of the extracellular $\alpha 1-\alpha 3$ domains of the CD1d $\alpha$-chain, and the $\beta_{2}$ microglobulin $\left(\beta_{2} \mathrm{M}\right)$ chain complexed to KRN7000, KRN7000@CD1d (1ZT4), ${ }^{39}$ we solvated the system, then minimized the structure. The resulting conformation remains substantially the same as in the crystal, although we note that the sugar sinks a bit deeper into the pocket in the simulation (Figure 4A). We then deleted KRN7000 and redocked it, then minimized the structure complexes followed by a 10ns molecular dynamic simulation to relax the geometry (Figure S2). This matches the crystal structure with high fidelity. The 2@CD1d and 2@CD1d structures were obtained by modifying the KRN7000@CD1d structure followed by a short molecular dynamics simulation and an optimization of the structure. The extracellular domain of CD1d consists of a $C$-terminal domain, containing two layers of $\beta$-sheets (blue and purple, Figure 4), linked to a more structurally complex $N$-terminal binding domain comprising two helices acting as a 'jaw' that hinges shut over a $\beta$-sheet floor. This jaw is widest in the centre, which determines the position of the carbohydrate of a bound glycolipid, while the long alkyl chains can sprawl into the two large hydrophobic cavities (pockets $\mathbf{A}$ and $\mathbf{C}$ ) formed between the helices and the $\beta$-sheet floor, to the left and right of the jaw's centre. 


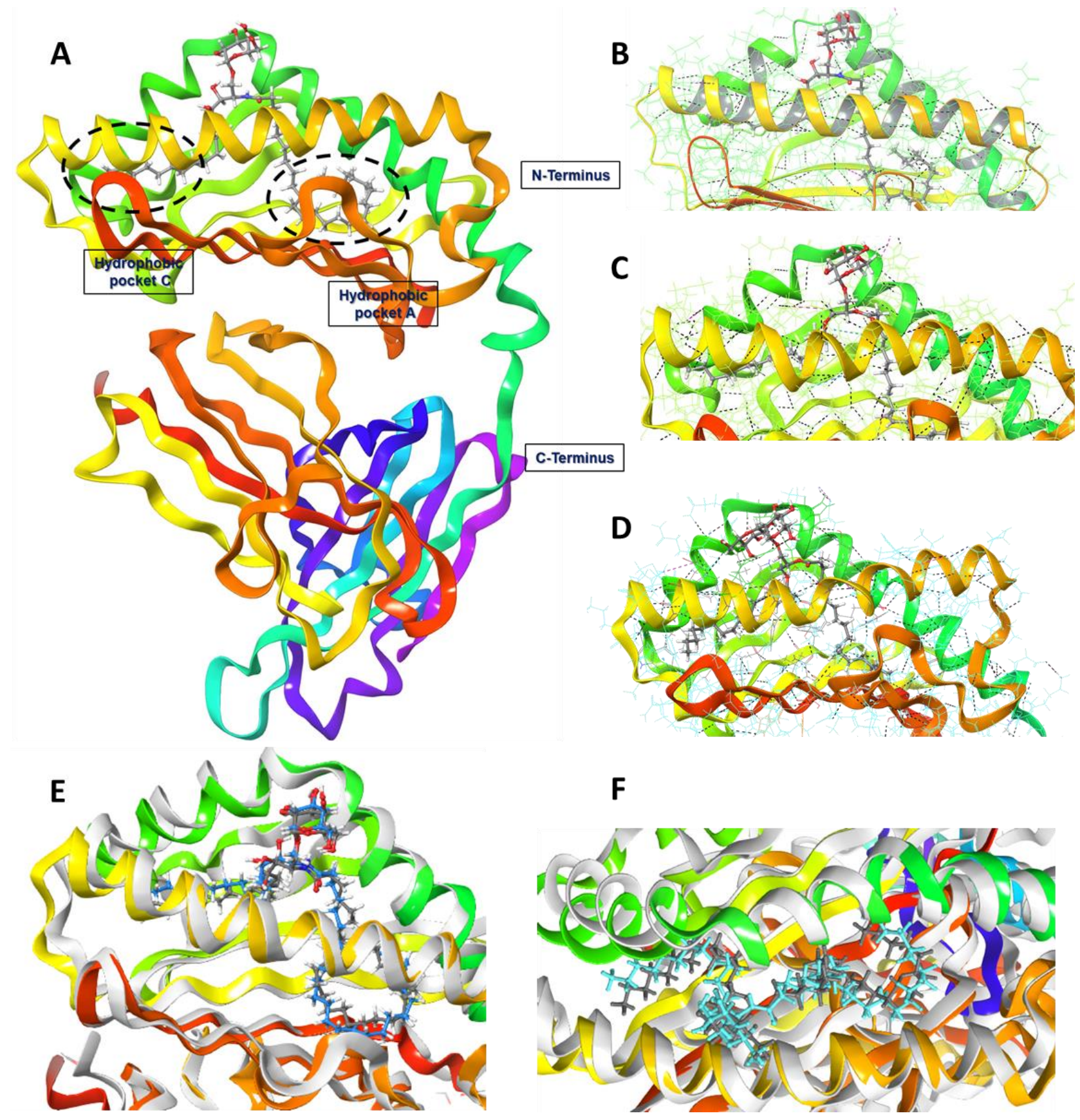

Figure 4. Comparison of the binding modes of the ligands to CD1d.

A) Relaxed structure of the complete protein bound to KRN7000, 1, (KRN7000@CD1d), highlighting the two hydrophobic pockets in the binding groove and the slightly folded down nature of the sugar relative to the crystal structure. B) Focus on the hydrogen bond interactions around the binding site with 1; C and D) Focus on the hydrogen bond interactions around the binding site with 2 and 3 respectively; E) Side-on view of the superimposition of the modelled KRN7000@CD1d onto PDB: 1ZT4. ${ }^{39}$ 
A number of residues position the chains of the binding glycolipid into the pocket, but the polar head group is held in place through a series of hydrogen bond interactions, such as that between the amide of the sphingosine with Thr154 (as either H-bond donor with the glycosidic oxygen atom or a H-bond acceptor with the 2'-NH amide moiety) and Asp151 of the a2-helix (Figure S1); the simulation is consistent with previous examples in the literature. ${ }^{40}$ The generated H-bond interactions originated from 2-OH, Thr154, Asp151, and 2'-NH have been shown to play important roles in localizing the polar head group. Similarly, the 3 '-OH of the phytosphingosine interacts with Asp80 of the $\alpha 1$-helix, positioning it above the groove. These H-bonding networks, of course, do not exist for the synthetic diglycerides. The main effect this has is that many of these interactions with these rim-residues are taken over by the carbohydrate instead of the phytosphingosine residues. This sinks the sugars deeper into the groove, decreasing their apparent surface (Figure 5), such that they don't extrude from the mouth as far as KRN7000.

With KRN7000, Trp153 of the $\alpha 2$-helix lies against the more hydrophobic bottom face of galactose, ensuring it orients in the right direction. It is able to do this with $\mathbf{3}$ as well but as this ligand sits deeper, the torsional bend in the angle is greater, twisting it from coplanar with the groove's floor, to a greater degree. This is further exacerbated as Asp151 then pulls down the sugar though interactions with the $\mathrm{C}-2 \mathrm{OH}$ of the pendent galactose residue, greatly distorting the positioning of the helix relative to the polar head group compared to KRN7000. For 2 the effect is even more drastic as the hexose slides over so that the C3-OH can interact with Asp151, meaning that Trp153 can do little to position the sugar as it is more distant. Finally, Asp80, so central for guiding KRN7000 into the groove, is now located far from the glycolipids of the diglycerides, and instead of binding to the $\mathrm{OH}$ of phytosphingosine, interacts with an adjacent arginine on the $\alpha 1$ helix.

The alkyl chains of these pneumococcal glycolipids do extend down the binding grooves, but they occupy them differently. KRN7000 has the exceedingly long 25-carbon amide alkyl group that curls around, filling the end of the A-pocket, and sinking deeper into it. This is a large cavity, and it is not satisfied by the far shorter cis-vaccenic acid residues. This likely contributes to a lower binding affinity, that although not determined in this, or other, studies, could be partially responsible for the lower observed activity. There are certainly differences in the energy of binding (Figure 5d). We measured the binding affinity of the ligands for the receptor relative to each other, using MM/GBSA calculations from the molecular dynamics simulations (Figure S3), with two 
separate techniques. The $\Delta \mathrm{G}$ measures the binding affinity from the native structures of relaxed ligand to the relaxed receptor, with both then compromising to adopt the docked structure. In all cases, this is extremely exothermic and extremely favourable; however, KRN7000 binds stronger than either of the other two ligands. Our second measurement examines the binding energies when the two species are frozen into their binding conformation $\Delta \mathrm{G}(\mathrm{NS})$. This "no strain" measurement directly measures the energy gain primarily from desolvation and the formation of the intermolecular interactions. In both cases, KRN7000 is the far stronger binder. The binding predictions show that the expected binding difference between the disaccharide 3 and KRN7000 is very minor. Again, there is no significant difference in the need to rearrange to form the complex from the minimal energy conformation of both species; the disaccharide needs the least adjustment to form the binding species. Differences in activation of the iNKt system does not likely arise from differences in binding. All bind well, the difference is likely in how the ligands are presented.

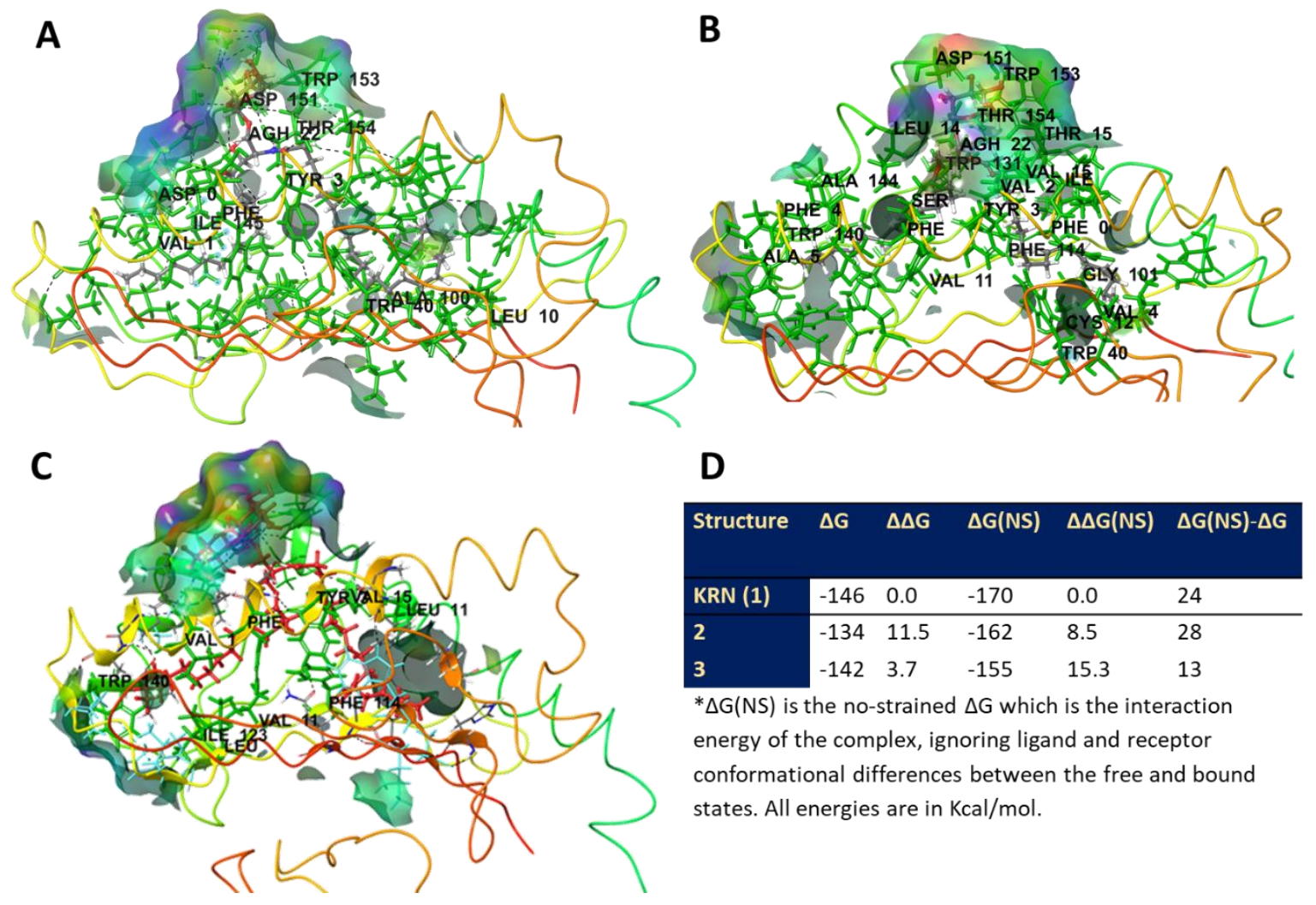

Figure 5. Plots of the electrostatic surface of the first hydration sphere around the binding groove of the complexes of A) KRN7000@CD1d, B) 2@CD1d; and C) 3@CD1d; D) Results of the energy calculations using MMGBSA of the dimer. 
Far more important than binding energy, might be in the exposed surface for ternary complex formation of TCRกKRN7000@CD1d (Figure 5). Plotting the surface of the dimer KRN7000@CD1d, shows that it is quite different for vs the other two glycolipids as they sit deeper in the groove as the key interactions are with the sugar itself and not the phytosphingosine residues. This would be partially compensated for if the sugar present was a galactoside as the C4$\mathrm{OH}$ would project out towards solvent, but as this is glucose, we lack this extended volume, shrinking the surface significantly relative to KRN7000. We know that the phytosphingosine residues (specifically the 2'- and 3'-OH) are essential for activity via T-cell recognition (Figure $3),{ }^{41}$ and that modification of them weakens the key interactions resulting in loss of activity. We know that the invariant T-cell receptor for CD1d is highly selective for the glycolipid guest in the CD1d receptor, and this selectivity could mean that it is not able to be activated by these residues. To explore this idea, we investigated the ternary complexes computationally (Figure 6).

Minimizing the energy of the TCRกKRN7000@CD1d (Figure 6A, expansion in 6B) shows how the $\mathrm{C}-4$ of the galactose sticks up towards the receptor, pushing the T-cell receptor up and away from the CD1d surface at that point (additional visualizations are provided as Figure S4). It is notable that if the carbohydrate rotated from this point, it would interfere with the required binding surface between the other two partners. This is the preferred interaction mode; exchange of the acyl groups would change the positioning of the sugar, and this would prevent the binding from occurring (as has been noted, swapping the acyl groups on the glycerol doesn't change the pocket preference, so it would change how the sugar sits in the pocket, and it would interfere with ternary complex formation). Glycolipid 2 can sit in the pocket (Figure 6C), but the TCR lowers further onto CD1d. The effect this has on the activation of the receptor is beyond the scope of this work, but it is not the same binding mode, although very similar. One can note that it not only sits deeper in the groove, but it distorts the relative positions of the beta sheets of the two proteins. KRN7000 sits inside the turn between the two alpha helices of the right side of the binding pocket, while 2 sits over this turn. Similarly, the beta sheet of the TCR in orange interacts directly over the ring of the carbohydrate in KRN7000, while we predict it sits over C4 in 2. This overall drags the TCR to the right relative to the Cd1D. Glycolipid 3 has the carbohydrate spilling over the alpha helix junction, and distorts the beta sheet of the TCR even further to the right (Figure 6D). This would be expected to affect the TCR activation. These a small difference, but small differences affect the binding of systems. These differences can be quantified; the total binding surface of all 
systems is relatively similar with the disaccharide being slightly higher than the other two (Figure $6 \mathrm{E}$ ); however the surface of KRN7000 involved in receptor binding is larger than for the other two, and the surface of the receptor that binds it is smaller than for the other two; the protein binding pocket is better suited to fit the ligand and can tighten around it. This can also be seen as the total surface are of the system is smallest for KRN7000@CD1d. The other two ligands disruption of the surface can be quantified as well as observed qualitatively from the model. It is consistent that the TCR would respond differently to these ligands than it would to KRN7000. Perhaps a galactose derivative of $\mathbf{2}$ or $\mathbf{3}$ would show more potent activity.

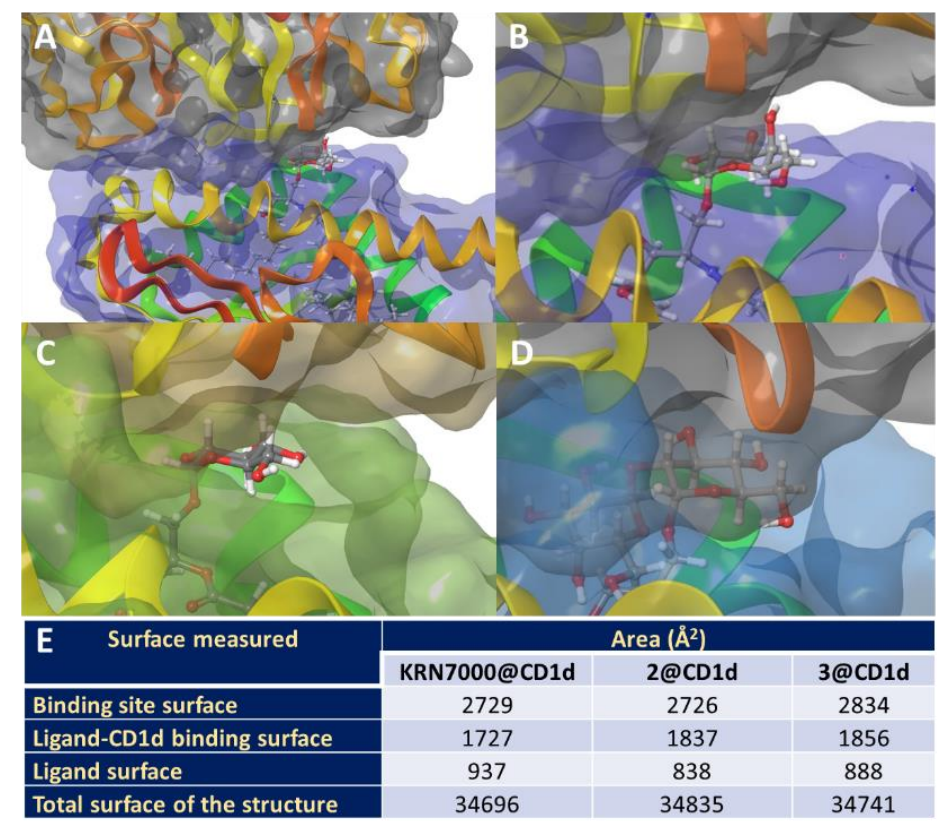

Figure 6. A plot of the calculated density surfaces of the TCR and CD1d in the ternary complexes

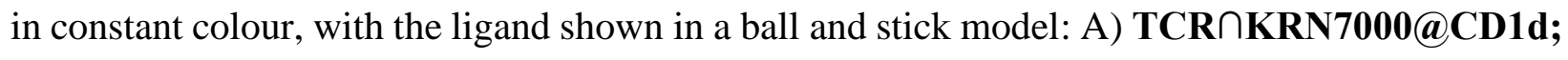
B) Expansion of the binding site of TCR $\cap K R$ N7000@CD1d; C) Expansion of the binding site of

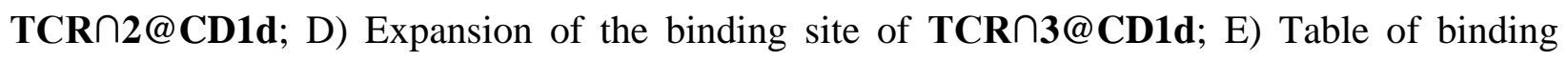
surface areas, defined as follows: Binding site surface is the total top surface of the antigen@CD1d outer surface available for binding to the TCR bounds were kept the same for all complexes to be directly comparable; Ligand-CD1d binding surface is the surface of the CD1d receptor interacting with the ligand; Ligand surface is the total surface area of the ligand; total structure surface is the surface of the complete antigen@CD1d combined outer surface (including the large component of the protein that sits into the membrane). 
Conclusions CD1d is an essential component of our intact immune system. It is almost certainly activated by the presence of bacterial glycolipids present in existential threat infectious agents such as $S$. pneumoniae. However, the isolated glycolipids $\mathbf{2}$ and $\mathbf{3}$ are not responsible for the observed activity. Their efficient synthesis and re-evaluation in this study provides a significant example for the need for the evaluation of synthetic rather than isolated samples as even a very small amount of impurity-undetectable on NMR $(<2 \%)^{42}$ can be responsible for observed activity. The changes to the interaction surface between the antigen@CD1d dimer and the T-cell receptor are significant and would modify the interaction. A re-analysis and repurification of these $S$. pneumoniae extracts searching for other known glycolipid activators of CD1d might prove very fruitful to explaining the existence of the invariant iNKT immune defense system.

Acknowledgements. The authors gratefully acknowledge financial support for the project from the Windsor Cancer Centre Foundation (2019-003), the Natural Sciences and Engineering Research Council of Canada (JFT: grant \# 2018-06338), the Canadian Tricouncil (NFRFE-201800075). SMT and JFT wish to recognize that this work was made possible by the facilities of the Shared Hierarchical Academic Research Computing Network (SHARCNET: www.sharcnet.ca) and Compute/Calcul Canada. The authors would like to thank Chelsea Ymana, and Science Meets Art UWindsor, for executing the TOC graphic. JFT would like to thank S. Mansour Haeryfar of the University of Western Ontario for initiating the idea behind this study.

Author Contributions. Conceptualization, JFT; Funding acquisition JFT, MR; Investigation, SIS, EI, GY, MK, SM, SMT, RA, JT; Methodology, SIS, SMT, MR, JFT; Visualization, SMT, MK, MR; Project administration, JFT, MR; Supervision, JFT, MR; Writing original draft, SIS, SMT, JFT, MR; Writing - review and editing, All authors.

\section{Reference}

1. Tao, L.; Reese, T. A., Making mouse models that reflect human immune responses. Tr. Immunol. 2017, 38 (3), 181-193. DOI: http://doi.org/10.1016/j.it.2016.12.007

2. Salio, M.; Silk, J. D.; Yvonne Jones, E.; Cerundolo, V., Biology of CD1- and MR1-Restricted T Cells. Ann. Rev. Immunol. 2014, 32, 323-366. DOI: http://doi.org/10.1146/annurev-immunol-032713-120243

3. (a) Brennan, P. J.; Brigl, M.; Brenner, M. B., Invariant natural killer T cells: An innate activation scheme linked to diverse effector functions. Nat. Rev. Immunol. 2013, 13 (2), 101-17. DOI: http://doi.org/10.1038/nri3369 ; (b) Tashiro, T.; Mori, K., Glycosphingolipid Ligands for Invariant Natural Killer T cells as Immunostimulants. In Studies in Natural Products Chemistry, Elsevier: 2014; Vol. 42, pp 131. DOI: http://doi.org/10.1016/B978-0-444-63281-4.00001-X

4. Natori, T.; Morita, M.; Akimoto, K.; Koezuka, Y., Agelasphins, novel antitumor and immunostimulatory cerebrosides from the marine sponge Agelas mauritianus. Tetrahedron 1994, 50 (9), 2771-2784. DOI: $\underline{\text { http://dx.doi.org/10.1016/S0040-4020(01)86991-X }}$ 
5. Birkholz, A. M.; Kronenberg, M., Antigen specificity of invariant natural killer T-cells. Biomed. J. 2015, 38 (6), 470-83. DOI: http://doi.org/10.1016/j.bj.2016.01.003

6. Banchet-Cadeddu, A.; Henon, E.; Dauchez, M.; Renault, J.-H.; Monneaux, F.; Haudrechy, A., The stimulating adventure of KRN 7000. Org. Biomol. Chem. 2011, 9 (9), 3080-3104. DOI: http://dx.doi.org/10.1039/c0ob00975j

$7 . \quad$ (a) Novak, J.; Lehuen, A., Mechanism of regulation of autoimmunity by iNKT cells. Cytokine 2011, 53 (3), 263-70. DOI: http://doi.org/10.1016/j.cyto.2010.11.001 ; (b) Crosby, C. M.; Kronenberg, M., Invariant natural killer T cells: Front line fighters in the war against pathogenic microbes. Immunogenetics 2016, 68 (8), 639-48. DOI: http://doi.org/10.1007/s00251-016-0933-y ; (c) Nieuwenhuis, E. E.; Matsumoto, T.; Exley, M.; Schleipman, R. A.; Glickman, J.; Bailey, D. T.; Corazza, N.; Colgan, S. P.; Onderdonk, A. B.; Blumberg, R. S., CD1d-dependent macrophage-mediated clearance of Pseudomonas aeruginosa from lung. Nat. Med. 2002, 8 (6), 588-93. DOI: http://doi.org/10.1038/nm0602-588

8. Kinjo, Y.; Illarionov, P.; Vela, J. L.; Pei, B.; Girardi, E.; Li, X.; Li, Y.; Imamura, M.; Kaneko, Y.; Okawara, A.; Miyazaki, Y.; Gomez-Velasco, A.; Rogers, P.; Dahesh, S.; Uchiyama, S.; Khurana, A.; Kawahara, K.; Yesilkaya, H.; Andrew, P. W.; Wong, C.-H.; Kawakami, K.; Nizet, V.; Besra, G. S.; Tsuji, M.; Zajonc, D. M.; Kronenberg, M., Invariant natural killer T cells recognize glycolipids from pathogenic Gram-positive bacteria. Nat. Immunol. 2011, 12 (10), 966-974. DOI: http://dx.doi.org/10.1038/ni.2096

9. Cherazard, R.; Epstein, M.; Doan, T.-L.; Salim, T.; Bharti, S.; Smith, M. A., Antimicrobial resistant Streptococcus pneumoniae: Prevalence, mechanisms, and clinical implications. Am. J. Ther. 2017, 24 (3), e361-e369. DOI: http://doi.org/10.1097/mjt.0000000000000551

10. Gray, B. M.; Musher, D. M., The History of Pneumococcal Disease. In Pneumococcal Vaccines, American Society of Microbiology: 2008. DOI: http://doi.org/10.1128/9781555815820.ch1

11. Field, C. J.; Blewett, H. H.; Proctor, S.; Vine, D., Human health benefits of vaccenic acid. Appl. Physiol. Nutr. Metab. 2009, 34 (5), 979-991. DOI: http://doi.org/10.1139/H09-079

12. Shimamura, M.; Hidaka, H., Therapeutic potential of cholesteryl O-acyl-alpha-glucoside found in Helicobacter pylori. Curr. Med. Chem. 2012, 19 (28), 4869-4874. DOI: http://dx.doi.org/10.2174/092986712803341502

13. Personal communication to JF Trant from S. Williams, February 7, 2021.

14. Richardson, M. B.; Smith, D. G.; Williams, S. J., Quantitation in the regioselectivity of acylation of glycosyl diglycerides: Total synthesis of a Streptococcus pneumoniae $\alpha$-glucosyl diglyceride. Chem. Commun. (Camb) 2017, 53 (6), 1100-1103. DOI: http://doi.org/10.1039/c6cc09584d

15. (a) Burugupalli, S.; Almeida, C. F.; Smith, D. G. M.; Shah, S.; Patel, O.; Rossjohn, J.; Uldrich, A. P.; Godfrey, D. I.; Williams, S. J., $\alpha$-Glucuronosyl and $\alpha$-glucosyl diacylglycerides, natural killer T cell-activating lipids from bacteria and fungi. Chem. Sci. 2020, 11 (8), 2161-2168. DOI: http://doi.org/10.1039/C9SC05248H ; (b) Almeida, C. F.; Sundararaj, S.; Le Nours, J.; Praveena, T.; Cao, B.; Burugupalli, S.; Smith, D. G. M.; Patel, O.; Brigl, M.; Pellicci, D. G.; Williams, S. J.; Uldrich, A. P.; Godfrey, D. I.; Rossjohn, J., Distinct CD1d docking strategies exhibited by diverse Type II NKT cell receptors. Nat. Commun. 2019, 10 (1), 5242. DOI: http://doi.org/10.1038/s41467-019-12941-9

16. Webb, A. J.; Karatsa-Dodgson, M.; Gründling, A., Two-enzyme systems for glycolipid and polyglycerolphosphate lipoteichoic acid synthesis in Listeria monocytogenes. Mol. Microbiol. 2009, 74 (2), 299-314. DOI: http://doi.org/10.1111/j.1365-2958.2009.06829.x

17. Dragalin, I. P.; Kintia, P. K., Steroidal saponins of Yucca filamentosa. Yuccoside C and protoyuccoside C. Phytochemistry 1975, 14 (8), 1817-20. DOI: http://doi.org/10.1016/00319422(75)85301-5

18. (a) Pozsgay, V.; Kubler-Kielb, J.; Coxon, B.; Marques, A.; Robbins, J. B.; Schneerson, R., Synthesis and antigenicity of BBGL-2 glycolipids of Borrelia burgdorferi, the causative agent of Lyme disease. Carbohydr. Res. 2011, 346 (12), 1551-1563. DOI: http://doi.org/10.1016/i.carres.2011.04.045 ; (b) Ghosh, B.; Lai, Y. H.; Shih, Y. Y.; Pradhan, T. K.; Lin, C. H.; Mong, K. K. T., Total synthesis of a glycoglycerolipid from 
Meiothermus taiwanensis through a one-pot glycosylation reaction and exploration of its immunological properties. Chem. Asian J 2013, 8 (12), 3191-3199. DOI: http://doi.org/10.1002/asia.201300933 ; (c) Cao, B.; Chen, X.; Yamaryo-Botte, Y.; Richardson, M. B.; Martin, K. L.; Khairallah, G. N.; Rupasinghe, T. W.; O'Flaherty, R. M.; O'Hair, R. A.; Ralton, J. E.; Crellin, P. K.; Coppel, R. L.; McConville, M. J.; Williams, S. J., Synthesis, structural elucidation, and biochemical analysis of immunoactive glucuronosyl diacylglycerides of mycobacteria and corynebacteria. J. Org. Chem. 2013, 78 (6), 2175-90. DOI: http://doi.org/10.1021/j0302508e ; (d) Stamatov, S. D.; Stawinski, J., O-Silylated C3-halohydrins as a novel class of protected building blocks for total, regio- and stereocontrolled synthesis of glycerolipid frameworks. Org. Biomol. Chem. 2010, 8 (2), 463-477. DOI: http://doi.org/10.1039/b915533c

19. Jefferson, T., The Papers of Thomas Jefferson, Retirement Series Vol 5. Duane, W., Ed. Princeton Press: Princeton, NJ, 1812; pp 293-294.

20. Ohlsson, J.; Magnusson, G., Galabiosyl donors; efficient synthesis from 1,2,3,4, 6-penta-O-acetylbeta-D-galactopyranose. Carbohydr. Res. 2000, 329 (1), 49-55. DOI: http://doi.org/10.1016/s00086215(00)00154-3

21. Katoch, R.; Trivedi, G. K.; Phadke, R. S.; chemistry, m., 1-[2-Hydroxy-3-octadecan-1'-oate] propyl2 ", 2 ", 5 ", 5 "-tetramethyl Pyrolidine-N-oxyl-3 "-carboxylate as a potential spin probe for membrane structure studies. Bioorg. Med. Chem 1999, 7 (12), 2753-2758. DOI: http://doi.org/10.1016/s09680896(99)00216-3

22. The reaction was attempted using 4 different batches of starting material, by 5 different chemists, using 3 different fresh bottles of sodium periodate. Starting material proceeded directly to a complex mixture in all cases, and only trace amounts of the desired material were able to be isolated regardless of changes in temperature, solvent mixture, and additives. Lead (IV) acetate proceeds smoothly.

23. Sugawara, F.; Nakayama, H.; Strobel, G. A.; Ogawa, T., Synthetic studies on rhynchosporoside and related substances. Agr. Biol. Chem. 1986, 50 (9), 2251-2259. DOI: http://doi.org/10.1271/bbb1961.50.2251

24. Vijayasaradhi, S.; Singh, J.; Aidhen, I. S., An efficient, selective hydrolysis of terminal isopropylidene acetal protection by $\mathrm{Zn}\left(\mathrm{NO}_{3}\right) 2 \cdot 6 \mathrm{H}_{2} \mathrm{O}$ in acetonitrile. Synlett 2000, 2000 (01), 110-112. DOI: http://doi.org/10.1055/s-2000-6458

25. Duffy, P. E.; Quinn, S. M.; Roche, H. M.; Evans, P., Synthesis of trans-vaccenic acid and cis-9-trans11-conjugated linoleic acid. Tetrahedron 2006, 62 (20), 4838-4843. DOI: http://doi.org/10.1016/i.tet.2006.03.006

26. Manzo, E.; Ciavatta, M. L.; Pagano, D.; Fontana, A., An efficient and versatile chemical synthesis of bioactive glyco-glycerolipids. Tetrahedron Lett. 2012, 53 (7), 879-881. DOI: http://doi.org/10.1016/i.tetlet.2011.12.030

27. Oh Sweet Summer Child.

28. Yu, H.; Ensley, H. E., An efficient method for the preparation of glycosides with a free C-2 hydroxyl group from thioglycosides. Tetrahedron Lett. 2003, 44 (52), 9363-9366. DOI: http://doi.org/10.1016/j.tetlet.2003.09.230

29. Cox, D. J.; Smith, M. D.; Fairbanks, A. J., Glycosylation catalyzed by a chiral Bronsted acid. Org. Lett. 2010, 12 (7), 1452-5. DOI: http://doi.org/10.1021/ol1001895

30. Demchenko, A. V., Handbook of chemical glycosylation. Wiley: Weinheim, 2008; p 501.Â DOI: None assigned

31. Liu, Y.; Deng, S.; Bai, L.; Freigang, S.; Mattner, J.; Teyton, L.; Bendelac, A.; Savage, P. B., Synthesis of diglycosylceramides and evaluation of their iNKT cell stimulatory properties. Bioorg. Med. Chem. Lett. 2008, 18 (10), 3052-3055. DOI: http://doi.org/10.1016/j.bmcl.2007.12.067

32. Garcia, B. A.; Poole, J. L.; Gin, D. Y., Direct glycosylations with 1-hydroxy glycosyl donors using trifluoromethanesulfonic anhydride and diphenyl sulfoxide. J. Am. Chem. Soc. 1997, 119 (32), 7597-7598. DOI: http://doi.org/10.1021/ja971067y 
33. (a) Reese, C.; Stewart, J., Methoxyacetyl as a protecting group in ribonucleoside chemistry. Tetrahedron Lett. 1968, 9 (40), 4273-4276. DOI: http://doi.org/10.1016/S0040-4039(00)76405-7 ; (b) Hanamoto, T.; Sugimoto, Y.; Yokoyama, Y.; Inanaga, J., Ytterbium(III) triflate-catalyzed selective methanolysis of methoxyacetates: A new deprotective method. J. Org. Chem. 1996, 61 (13), 4491-4492. DOI: http://doi.org/10.1021/j0960095g ; (c) Rosseto, R.; Bibak, N.; DeOcampo, R.; Shah, T.; Gabrielian, A.; Hajdu, J., A new synthesis of lysophosphatidylcholines and related derivatives. Use of $p$-toluenesulfonate for hydroxyl group protection. J. Org. Chem. 2007, 72 (5), 1691-1698. DOI: http://doi.org/10.1021/jo062352f

34. (a) Hayworth, J. L.; Mazzuca, D. M.; Vareki, S. M.; Welch, I.; McCormick, J. K.; Haeryfar, S. M. M., CD1d-independent activation of mouse and human iNKT cells by bacterial superantigens. Immunol. Cell Biol. 2012, 90 (7), 699-709. DOI: http://doi.org/10.1038/icb.2011.90 ; (b) Szabo, P. A.; Anantha, R. V.; Shaler, C. R.; McCormick, J. K.; Haeryfar, S. M. M., CD1d- and MR1-restricted T cells in sepsis. Front. Immunol. 2015, 6, 401-401. DOI: http://doi.org/10.3389/fimmu.2015.00401 ; (c) Trant, J. F.; Jain, N.; Mazzuca, D.; McIntosh, J.; Fan, B.; Haeryfar, S. M. M.; Lecommandoux, S.; Gillies, E. R., Synthesis, selfassembly, and immunological activity of $\alpha$-galactose-functionalized dendron-lipid amphiphiles. Nanoscale 2016, 8, 17694-17704. DOI: http://doi.org/10.1039/c6nr05030a

35. (a) Mattner, J.; DeBord, K. L.; Ismail, N.; Goff, R. D.; Cantu, C.; Zhou, D.; Saint-Mezard, P.; Wang, V.; Gao, Y.; Yin, N.; Hoebe, K.; Schneewind, O.; Walker, D.; Beutler, B.; Teyton, L.; Savage, P. B.; Bendelac, A., Exogenous and endogenous glycolipid antigens activate NKT cells during microbial infections. Nature 2005, 434 (7032), 525-529. DOI: http://doi.org/10.1038/nature03408; (b) Tupin, E.; Kinjo, Y.; Kronenberg, M., The unique role of natural killer T cells in the response to microorganisms. Nat. Rev. Microbiol. 2007, 5, 405. DOI: http://doi.org/10.1038/nrmicro1657

36. Sadraei, S. I.; Reynolds, M.; Trant, J. F., The synthesis and biological characterization of acetal-free mimics of the tumour-associated carbohydrate antigens. Adv. Carbohydr. Chem. Biochem. 2017, 74, 137237. DOI: http://doi.org/10.1016/bs.accb.2017.10.003

37. Wolucka, B. A.; McNeil, M. R.; Kalbe, L.; Cocito, C.; Brennan, P. J., Isolation and characterization of a novel glucuronosyl diacylglycerol from Mycobacterium smegmatis. Biochim. Biophys. Acta, Lipids Lipid Metab. 1993, 1170 (2), 131-136. DOI: http://doi.org/10.1016/0005-2760(93)90062-E

38. Uldrich, A. P.; Patel, O.; Cameron, G.; Pellicci, D. G.; Day, E. B.; Sullivan, L. C.; Kyparissoudis, K.; Kjer-Nielsen, L.; Vivian, J. P.; Cao, B.; Brooks, A. G.; Williams, S. J.; Illarionov, P.; Besra, G. S.; Turner, S. J.; Porcelli, S. A.; McCluskey, J.; Smyth, M. J.; Rossjohn, J.; Godfrey, D. I., A semi-invariant V $\alpha 10+$ T cell antigen receptor defines a population of natural killer $\mathrm{T}$ cells with distinct glycolipid antigen-recognition properties. Nat. Immunol. 2011, 12 (7), 616-623. DOI: http://doi.org/10.1038/ni.2051

39. Koch, M.; Stronge, V. S.; Shepherd, D.; Gadola, S. D.; Mathew, B.; Ritter, G.; Fersht, A. R.; Besra, G. S.; Schmidt, R. R.; Jones, E. Y.; Cerundolo, V., The crystal structure of human CD1d with and without $\alpha-$ galactosylceramide. Nat. Immunol. 2005, 6 (8), 819-826. DOI: http://doi.org/10.1038/ni1225

40. Hénon, E.; Dauchez, M.; Haudrechy, A.; Banchet, A., Molecular dynamics simulation study on the interaction of KRN 7000 and three analogues with human CD1d. Tetrahedron 2008, 64 (40), 9480-9489. DOI: http://doi.org/10.1016/j.tet.2008.07.077

41. Borg, N. A.; Wun, K. S.; Kjer-Nielsen, L.; Wilce, M. C. J.; Pellicci, D. G.; Koh, R.; Besra, G. S.; Bharadwaj, M.; Godfrey, D. I.; McCluskey, J.; Rossjohn, J., CD1d-lipid-antigen recognition by the semiinvariant NKT T-cell receptor. Nature 2007, 448 (7149), 44-49. DOI: http://www.nature.com/nature/journal/v448/n7149/suppinfo/nature05907 S1.html

42. Wernerova, M.; Hudlicky, T., On the practical limits of determining isolated product yields and ratios of stereoisomers. Reflections, analysis, and redemption. Synlett 2010, (18), 2701-2707. DOI: http://doi.org/10.1055/s-0030-1259018 